\title{
PENGARUH PENERAPAN ELEKTRONIK SURAT PEMBERITAHUAN (e-SPT) TERHADAP EFISIENSI PENGISIAN SURAT PEMBERITAHUAN WAJIB PAJAK (Studi Kasus Pada SMK Negeri 2 Majene)
}

\author{
Oleh : \\ Dahlia \\ Dosen Program Studi Akuntansi Fakultas Ekonomi Universitas Sulawesi Barat \\ Email : dahlia@unsulbar.co.id
}

\begin{abstract}
Abstrak
Penelitian ini bertujuan untuk mengetahui pengaruh penerapan elektronik surat pemberitahuan (e-SPT) terhadap efisiensi pengisian surat pemberitahuan wajib pajak di SMK Negeri 2 Majene. Pengumpulan data dilakukan dengan menyebarkan kuesioner wawancara dan dokumentasi. Teknik analisis data yang digunakan yaitu Analisis Regresi Linear Sederhana.

Hasil penelitian yaitu Penerapan e-SPT berpengaruh positif dan signifikan terhadap efisiensi pengisian surat pemberitahuan wajib pajak oleh pegawai (guru dan staf) di SMK Negeri 2 Majene.
\end{abstract}

\begin{abstract}
This research aim to find the the effect of application of electronic notification letter (e-SPT) to the efficiency of filling taxpayer notice in SMK Negeri 2 Majene. Data collection technique is distributing questionnaires, interviews and documentation. The analytical method used are Simple Linear Regression Analysis.

The result showed that application of electronic notification letter (e-SPT) have a positive and significant effect to efficiency of filling taxpayer notice by employees (teachers and staff) in SMK Negeri 2 Majene.
\end{abstract}

\section{PENDAHULUAN}

Penerimaan pajak merupakan sumber pendapatan utama negara yang digunakan dalam pembiayaan dan pembangunan. Pemerintah mengikutsertakan masyarakat untuk berperan serta dalam pembiayaan keuangan negara melalui pemungutan pajak. Pajak bertujuan meningkatkan kesejahteraan rakyat melalui perbaikan dan peningkatan sarana publik.

Menurut Undang-Undang Ketentuan Umum dan Tata Cara Perpajakan dalam pasal 1 UU No. 28 Tahun 2007: "Pajak adalah kontribusi wajib kepada negara yang terutang oleh orang pribadi atau badan yang bersifat memaksa berdasarkan UndangUndang, dengan tidak mendapatkan imbalan secara langsung dan digunakan untuk keperluan negara bagi sebesarbesarnya kemakmuran rakyat."

Lembaga negara yang ditunjuk oleh pemerintah sebagai lembaga pengelola pajak adalah Direktorat Jenderal Pajak (DJP). Sebagai lembaga pengelola pajak, 
DJP melakukan beberapa reformasi dan inovasi sitem administratif demi meningkatkan pendapatan negara dari sektor pajak. Syarat mutlak dalam menuju kemandirian bangsa adalah dengan meningkatkan peran serta masyarakat melalui pembayaran pajak.

Sebagai bentuk peningkatan kualitas pelayanan perpajakan terhadap wajib pajak salah satunya dikembangkannya pelaporan pajak terutang dengan menggunakan elektronik SPT (e-SPT), sebagaimana surat keputusan direktur jenderal pajak nomor KEP-88/PJ./2004 tanggal 14 Mei 2004 (BN No. 7069 hal. 4B) tentang Penyampaian Surat Pemberitahuan secara Elektronik (eSPT).

SMK Negeri 2 Majene merupakan salah satu sekolah unggulan di Kabupaten Majene yang juga merupakan sekolah menengah kejuruan pada kelompok bisnis dan manajemen. Aparatur Sipil Negara pada SMK Negeri 2 Majene diharapkan bisa memanfaatkan fasilitas teknologi eSPT dalam pelaporan perpajakannya.

Berdasarkan latar belakang yang telah diuraikan maka tujuan dalam penelitian ini adalah untuk mengetahui bagaimana Pengaruh Penerapan Elektronik Surat Pemberitahuan (e-SPT) Terhadap Efisiensi
Pengisian Surat Pemberitahuan Wajib Pajak di SMK Negeri 2 Majene.

\section{METODE PENELITIAN}

\section{A. Variabel Penelitian}

1. Variabel bebas yaitu Penerapan e-SPT dengan indikator : kepraktisan, kemudahan perekaman data, kemudahan pemakaian, kemudahan perhitungan, kemudahan pelaporan .

2. Variabel terikat yaitu efisiensi pengisian SPT dengan indikator : tepat, cermat, hemat biaya waktu dan tenaga.

\section{B. Jenis dan Sumber Data}

Jenis data yang digunakan dalam penelitian ini adalah data primer sumber data penelitian yang diperoleh secara langsung dari sumber asli (tidak melalui media perantara) yang secara khusus dikumpulkan oleh peneliti.

\section{Populasi dan Sampel}

Populasi dalam penelitian ini adalah seluruh ASN (guru dan staf ) di SMK N 2 Majene yang berjumlah 65 orang. Jumlah populasi dalam penelitian ini kurang dari 100 sehingga seluruh populasi dijadikan sampel yaitu sebanyak 65 orang.

\section{Teknik Pengumpulan Data}

Teknik pengumpulan data yang digunakan dalam penelitian ini yaitu kuesioner, dokumentasi, dan wawancara. 


\section{E. Teknik analisis data}

\section{A. Uji Validitas dan reliabilitas}

Uji validitas menggunakan teknik Spearman. Menurut Sugiyono (2016:126) bila nilai korelasi dibawah 0,30 maka dapat disimpulkan bahwa butir instrument tersebut tidak valid. Sedangkan Uji reliabilitas yang akan dilakukan adalah dengan menggunakan Cronbach Alpha dengan standar minimal 0,60.

\section{B. Analisis Regresi Linear Sederhana}

Untuk mengetahui pengaruh Penerapan Elektronik Surat Pemberitahuan (e-SPT) Terhadap Efisiensi Pengisian Surat Pemberitahuan Wajib dilakukan uji regresi linear sederhana. Model penelitian yang digunakan dalam penelitian ini adalah :

$\mathbf{Y}=\mathbf{a}+\boldsymbol{\beta} \mathbf{X}+\mathbf{e}$

Keterangan :

$$
\begin{aligned}
& \mathrm{Y}=\text { Penerapan e-SPT } \\
& \mathrm{X}=\text { Efisiensi pengisian SPT } \\
& \mathrm{a}=\text { Konstanta } \\
& \beta=\text { Parameter/koefisien regresi } \\
& \mathrm{e}=\text { Error terms }
\end{aligned}
$$

\section{HASIL DAN PEMBAHASAN}
A. Hasil Penelitian
1. Uji validitas dan Reliabilitas

Dari hasil olah data terlihat bahwa nilai koefisien korelasi setiap item pertanyaan variabel penerapan e-SPT dan Efisiensi pengisian SPT lebih besar dari 0,30 sehingga dapat disimpulkan bahwa item pertanyaan yang digunakan valid.

Sedangkan berdasarkan uji reliabilitas terlihat nilai reliabilitas variabel penerapan e-SPT dan variabel efisiensi pengisian SPT terlihat lebih besar dari 0,60 sehingga dapat disimpulkan bahwa butir pertanyaan adalah handal untuk mengukur kedua variabel

\begin{tabular}{|c|c|c|c|c|c|}
\hline \multicolumn{6}{|c|}{ Coefficients $^{\mathrm{a}}$} \\
\hline \multirow[t]{3}{*}{ Model } & \multirow{2}{*}{\multicolumn{2}{|c|}{$\begin{array}{c}\text { Unstandardized } \\
\text { Coefficients }\end{array}$}} & Standardized & $\mathrm{T}$ & Sig. \\
\hline & & & Coefficients & & \\
\hline & B & $\begin{array}{l}\text { Std. } \\
\text { Error }\end{array}$ & Beta & & \\
\hline \multirow{2}{*}{$1 \begin{array}{l}\text { (Constant) } \\
\text { Efisiensi }\end{array}$} & 1,399 & ,378 & & 3,69 & ,000 \\
\hline & ,633 & ,094 & 649 & 6,77 & ,000 \\
\hline
\end{tabular}
tersebut.

\section{Analisis regresi linear sederhana}

Berdasarkan hasil olah data dengan menggunakan SPSS 20 diperoleh hasil :

a. Dependent Variable: e_SPT

Nilai konstanta sebesar 1,399 menunjukan bahwa jika penerapan e-SPT nilainya sebesar 0 satuan maka efisiensi pengisian SPT sebesar 1,399 satuan. Nilai koefisien regresi sebesar 0.633 menunjukkan bahwa jika penerapan e-SPT nilainya naik sebesar 1 satuan maka nilai 
efisiensi pengisian SPT akan meningkat sebesar 0,633 satuan.

\section{B. Pembahasan Hasil Penelitian}

Berdasarkan hasil olah data dapat diketahui bahwa nilai koefisien regresi sebesar 0,633 dengan signifikansi sebesar $0,000<0.05$ sehingga dapat disimpulkan bahwa penerapan e-SPT berpengaruh positif dan signifikan terhadap efisiensi pengisian SPT oleh pegawai (guru dan staf) di SMK Negeri 2 Majene.

Target penerimaan pajak dapat tercapai apabila didukung oleh fasilitas dan kepatuhan wajib pajak membayar kewajibannya. Salah satu fasilitas pajak dalam rangka modernisasi administrasi perpajakan adalah elektronik Surat Pemberitahuan (e-SPT) yang merupakan aplikasi (software) yang dibuat oleh Direktorat Jenderal Pajak untuk digunakan oleh wajib pajak untuk kemudahan dalam menyampaikan SPT Pajak yang terutang. Aplikasi e-SPT memiliki tujuan :

a. Data-data perpajakan dapat terorganisasi dengan baik dan sistematis;

b. Mempermudah dalam menghitung SPT dan pembuatan laporan perpajakan; c. Mudah dan efisien dalam pelaporan perpajakan.

Hasil penelitian ini sejalan dengan penelitian yang dilakukan oleh Muhamad Kubrajaya Kader dkk tahun 2015, Dimana hasil penelitiannya menunjukkan bahwa penerapan e-SPT berpengaruh positif dan signifikan terhadap efisiensi pengisian SPT.

\section{SIMPULAN}

Penerapan e-SPT berpengaruh positif dan signifikan terhadap efisiensi pengisian SPT oleh pegawai (guru dan staf ) di SMK Negeri 2 Majene.

\section{DAFTAR PUSTAKA}

Abdul H. (2016). Perpajakan. Jakarta. Salemba Empat

Kader M.K, Sabijono H., Wokas H.R.N. (2015), Pengaruh penerapan elektronik surat pemberitahuan (espt) terhadap efisiensi pengisian surat Pemberitahuan (spt) wajib pajak di kecamatan sario Kota manado. Jurnal Berkala Ilmiah Efisiensi. Volume 15 No. 04. Ekonomi Pembangunan - FEB Universitas Sam Ratulangi Manado.

Mardasmo. (2011). Perpajakan. Yogyakarta. Andi

Resmi, Siti. (2013), Perpajakan Teori dan Kasus, Jakarta. Salemba Empat

Sugiyono. (2016). Statistika Untuk Penelitian. Bandung. Alfabeta

Tamboto, Falerian R.A. (2013). Pengaruh Penerapan e-SPT PPN terhadap Efisiensi Pengisian SPT PPN menurut Persepsi Pengusaha Kena Pajak pada KPP Pratama Manado. Jurnal EMBA Vol. 1 No. 4 Desember 2013, Hal. 2059-2068. 
Undang Undang Republik Indonesia Nomor 28 tahun 2007 tentang Perubahan Ketiga atas Undang Undang Nomor 6 tahun 1983 tentang Ketentuan Umum dan Tata Cara Perpajakan. 